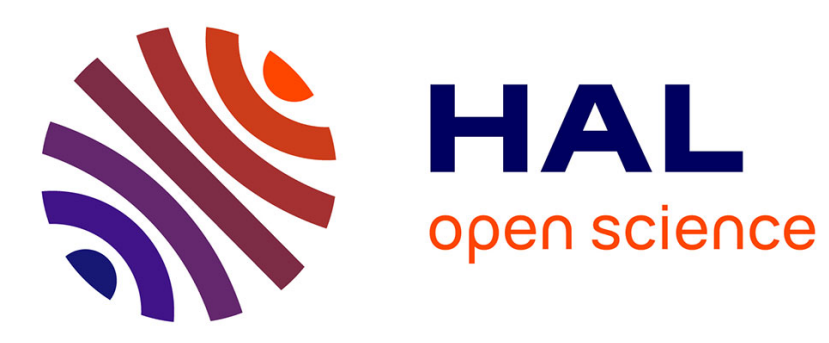

\title{
EMI estimation for DC/AC hard switching converter using Wiener filter
}

Piotr Musznicki, Jean-Luc Schanen, Pierre Granjon, Piotr Chrzan

\section{To cite this version:}

Piotr Musznicki, Jean-Luc Schanen, Pierre Granjon, Piotr Chrzan. EMI estimation for DC/AC hard switching converter using Wiener filter. 12th IEEE International Conference on Power Electronics and Motion Control (PEMC 2006), 2006, Portoroz, Slovenia. pp.473-478. hal-00021547v2

\section{HAL Id: hal-00021547 \\ https://hal.science/hal-00021547v2}

Submitted on 24 May 2006

HAL is a multi-disciplinary open access archive for the deposit and dissemination of scientific research documents, whether they are published or not. The documents may come from teaching and research institutions in France or abroad, or from public or private research centers.
L'archive ouverte pluridisciplinaire HAL, est destinée au dépôt et à la diffusion de documents scientifiques de niveau recherche, publiés ou non, émanant des établissements d'enseignement et de recherche français ou étrangers, des laboratoires publics ou privés. 


\title{
EMI estimation for DC/AC hard switching converter using Wiener filter
}

\author{
Piotr Musznicki*, Jean-Luc Schanen ${ }^{\dagger}$, Pierre Granjon ${ }^{\ddagger}$, Piotr J. Chrzan* \\ *Politechnika Gdańska,Wydział Elektrotechniki i Automatyki KEiME, \\ ul Sobieskiego 7, 80-216 Gdansk, pmusz@ely.pg.gda.pl \\ ${ }^{\dagger}$ Laboratoire d'Electrotechnique de Grenoble, \\ UMR 5529 INPG/UJF - CNRS, ENSIEG BP 46 - 38402 Saint-Martin-d'Hères Cedex, jean-luc.schanen@leg.ensieg.inpg.fr \\ $\ddagger$ Laboratoire des Images et des Signaux, \\ INPG, BP46, 38402 St Martin d'Hères, pierre.granjon@lis.inpg.fr
}

\begin{abstract}
This paper describes how the use of a specific signal processing method can help to estimate and understand the Electromagnetic Interference (EMI) generation of a switched mode power supply. This method allows to estimate, from EMI measurements, the different transfer functions between each source of disturbance and the disturbances themselves. Thus, the EMI signals is decomposed and combined with independent source of disturbances. This method is based on the redefinition of the voltage source inverter switching states, and on the Wiener filtering theory. This new tool for fast EMI estimation and prediction is fist described, and its performance is illustrated on simulated and measured data.
\end{abstract}

\section{INTRODUCTION}

It has been well recognized that switching phenomena in power electronics converters are at the origin of EMI generation. The reduction of this emission to meet the international standards necessitates better understanding of EMI generation and propagation process. Several authors have tried to investigate this aspect, using various experiments and/or simulations in time or frequency domain:

- simulation of whole circuit with many simplifications in parasitic calculation [1], [2], [3],

- estimation of simplified schema consisted of only the most important components [7], [9].

In previous papers in order to forecast perturbation, authors used only one transfer function between switch and the line impedance stabilization network (LISN) voltage [7], [10]. In authors opinion, such a simplification is too strong and in some cases could lead to incorrect results. In this paper the new technique of fast EMI reconstruction and prediction, that allows fast and more accurate estimation of the EMI emission for a power electronic application is presented. Starting from digital signal processing basis, we aim to determine the contribution to perturbations level from switch turn on and turn off. This digital signal processing method is based on powerful Wiener filtering approach [4], that links the source of disturbances and noise measured on LISN.

In this way, EMI behavior of power electronic inverter in the range of conducted perturbation frequency (defined from $10 \mathrm{kHz}$ to $30 \mathrm{MHz}$ ) is represented by the system, which contains transfer functions between semiconductor devices and perturbations. This allows to quantify the electromagnetic disturbance of each independent switch (eg. MOSFET, IGBT, diode), to estimate the propagation path of this disturbance at each time, moreover find the contribution of the disturbance source on the global EMI generation and propagation.

\section{SPECIFYING INVERTER STATES}

The perturbation from power electronic converters are generated during semiconductors turn on or turn off. The fast rated change of voltage on one of circuit elements is the reason for perturbation that appears and can be registered on the LISN. Standardized LISN is typically used for perturbation measurements generated in power electronic applications. The level and waveforms of perturbations depend not only on voltage $(\mathrm{dv} / \mathrm{dt})$ and current (di/dt) rise or fall time, but also propagation path has influence on it. Parasitics of all components can not be neglected, including parasitic capacitances and inductances of semiconductors and passive components, inductance of connection and conducting tracks and also capacitances to the ground.

In this method, the following assumptions have been adopted:

- perturbation is the result of commutation of only one switch, but level and waveform of perturbations strongly depends on state of residual semiconductors,

- transistors in parallel branches cannot be switch in exactly the same time instant, what is quite typical in modern power electronic applications.

The perturbation paths can be different owing to various parasitics which take part in propagation. The waveform during commutation of first transistor, when neighboring switch is open, is not the same with closed one because values of parasitic capacitances and propagation paths are different. The states of all semiconductor devices have influence on perturbation level. So, it can be concluded that the level of perturbation generated during commutation of one switch is strongly depended on states of all inverter switches.

Therefore, the transfer function between source of perturbation and perturbation registered on the LISN is 
depended on all circuit parameters and state of inverter. It can be also noticed that values of all components are time invariant during typical inverter operation, but only inverter state is changing.

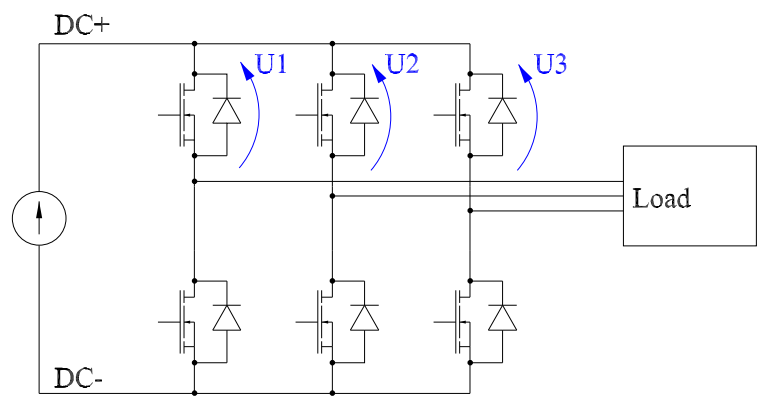

Fig. 1. Voltages used to inverter state definition.

Conventionally, the eight states of three phase bridge inverter can be defined in accordance with voltage space vector which is produced on the output of converter. However, this approach is not useful for EMI analyzes, because it is impossible to find which semiconductor device is a source of disturbances. In this paper, we defined a new method of states determination based on voltages between one of busbar DC+ or DC- and output midpoints of three parallel inverter legs (fig.1). These voltages can be easily obtained by computer simulations and they are available for measurement in a large majority of real applications. The proposed approach allows to define 12 states and to determinate 12 transfer function

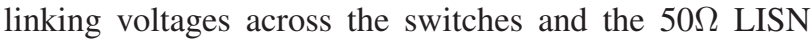
resistor, in order to forecast perturbation waveforms.

When commutation happens in first leg (transistor or diode is turn on or turn off), the other semiconductor devices are on (low voltage) or off (high voltage). Regarding only $U_{2}$ and $U_{3}$ level, four different inverter state can be defined for one switch commutation $d U_{1} / d t \neq 0$ (table I). These states are different because propagation paths are different resulting from inside capacitances of semiconductors changes.

TABLE I

CONVERTER STATES DEFINITION FOR $U_{1}$ CHANGE.

\begin{tabular}{|c|c|c|c|}
\hline state & $U_{1}$ & $U_{2}$ & $U_{3}$ \\
\hline 1 & change & high & high \\
\hline 2 & -- & high & low \\
\hline 3 & -- & low & high \\
\hline 4 & -- & low & low \\
\hline
\end{tabular}

Analogously, next states are defined for commutations in remaining legs, when $U_{2}$ and $U_{3}$ are changing (table II).To conclude, for accurate forecasting of EMI perturbations generated in hard switching inverter, the 12 states should be distinguished for different propagation paths. Moreover,perturbations spread in a different way, when the switch is turn on or turn off. It provides that total
TABLE II

CONVERTER STATES DEFINITION FOR $U_{2}$ AND $U_{3}$ CHANGE.

\begin{tabular}{|c|c|c|c|}
\hline state & $U_{1}$ & $U_{2}$ & $U_{3}$ \\
\hline 5 & high & change & high \\
\hline 6 & high & -- & low \\
\hline 7 & low & -- & high \\
\hline 8 & high & -- & low \\
\hline 9 & high & high & change \\
\hline 10 & high & low & - \\
\hline 11 & low & high & - \\
\hline 12 & high & low & - \\
\hline
\end{tabular}

number of states should be doubled, finally leading to the 24 states. This method can be used to reconstruct inverter perturbation waveforms, for all kind of modulation. There is no need to check, which semiconductor - transistor or diode - actually conduct the current in chosen inverter leg. Furthermore, dead time phenomena is taken into account.

\section{WIENER FILTER IN EMI ESTIMATION}

The general method of Wiener filtering [8] applied to EMI estimation is described in Fig. 2. The aim is better

disturbances

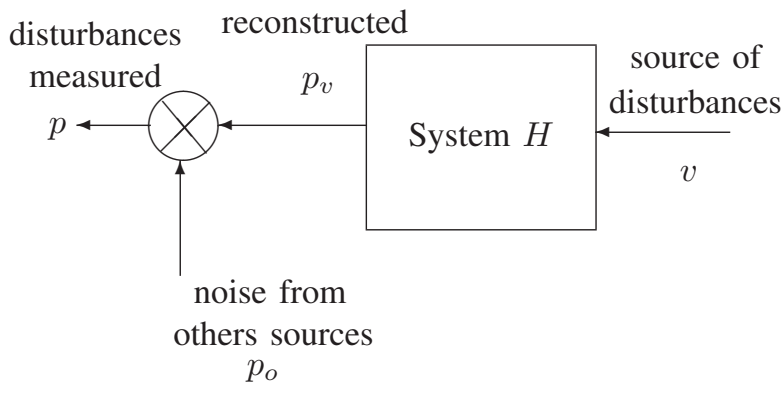

Fig. 2. Wiener filtering applied to EMI estimation

achieve two objects: to estimate on the one hand the system $H$, and on the other hand the disturbance $p_{v}$ by measuring only two signals

- the source of disturbances $v$ (which is one of the voltages $U_{1}, U_{2}$ or $U_{3}$ defined in Fig. 1),

- the total disturbance $p$, measured on the LISN.

The main assumptions of Wiener filtering theory are as follows:

- the unknown system $H$ is linear and time-invariant, which means that it can be completely described by its frequency response or its impulse response,

- the noise due to other sources of disturbance $p_{o}$ is additive and not correlated with measured signals $p$ and $v$.

Thanks to the previous model and assumptions, all signals can be easily expressed in the frequency domain. Indeed, the Fourier transform of the disturbance $p_{v}$, noted $P_{v}(j \omega)$, is expressed as:

$$
P_{v}(j \omega)=H(j \omega) V(j \omega),
$$


where $V(j \omega)$ is the Fourier transform of $v$ and $H(j \omega)$ is the frequency response of $H$.

The estimation error $E_{r}(j \omega)$ is defined as the difference between the measured disturbance $P(j \omega)$ and the reconstructed one $P_{v}(j \omega)$ :

$$
\begin{aligned}
E_{r}(j \omega) & =P(j \omega)-P_{v}(j \omega) \\
& =P(j \omega)-H(j \omega) V(j \omega)
\end{aligned}
$$

The mean square error between measured and reconstructed disturbances can now be defined in the frequency domain as:

$$
\begin{aligned}
E\left[\left|E_{r}(j \omega)\right|^{2}\right]= & E\left[(P(j \omega)-H(j \omega) V(j \omega))^{*}\right. \\
& (P(j \omega)-H(j \omega) V(j \omega))],
\end{aligned}
$$

where $E[\cdot]$ denotes the expectation operator and * the complex conjugate.

The aim is to find the optimal value of the frequency response which minimizes this error. Therefore, the derivative of Eq. (3) is calculated with respect to $H(j \omega)$ by using complex derivative rools, which leads to [8]:

$$
\frac{\partial E\left[\left|E_{r}(j \omega)\right|^{2}\right]}{\partial H(j \omega)}=2 H(j \omega) S_{v v}(j \omega)-2 S_{v p}(j \omega),
$$

where $S_{v v}(j \omega)=E\left[|V(j \omega)|^{2}\right]$ is the power spectrum of $v$, and $S_{v p}(j \omega)=E\left[P(j \omega) V^{*}(j \omega)\right]$ is the cross spectrum between $v$ and $p$.

The optimal value $H_{o}(j \omega)$, for which this derivative is zero, is the frequency response of the optimal or Wiener filter. Its expression in the frequency domain is given by:

$$
H_{o}(j \omega)=\frac{S_{v p}(j \omega)}{S_{v v}(j \omega)}
$$

The same study can also be carried out in the time domain [8]. In this case, the impulse response of the Wiener filter is obtained as a function of the autocorrelation function of $v$ and the crosscorrelation function between $v$ and $p$.

These results show that the optimal filter only depends on quantities that can be estimated from measured signals $v$ and $p$ : their auto- and cross- spectra or correlation functions. Once this filter is estimated, it can easily be applied to $v$ in order to best estimate the unknown signal $p_{v}$. In this application, $p_{v}$ represents the EMI only generated by the source $v$, i.e. denoised from the EMI $p_{o}$ which is generated by the other components of the inverter.

In order to forecast EMI disturbances in the particular DC/AC hard switching converter using Wiener filtering method, the 24 transfer functions should be calculated (see Fig. 3) for turn on and turn off for each of 12 inverter states (see Tables I and II).

The signal recorded on LISN is decomposed on blocks. One block contains samples from time period between two neighboring commutations. In order to apply Wiener filtering, each block is linked with one of 24 systems, depending on inverter state and direction of commutation. For each system, the voltages across the one switch (from leg where commutation occurs) and LISN are used to calculate transfer function.

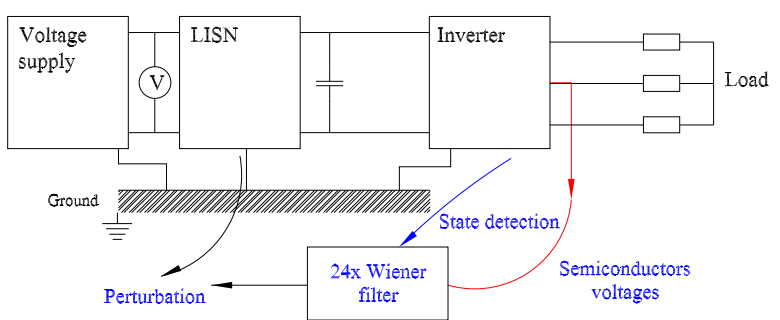

Fig. 3. Wiener filters and the inverter

\section{VALIDATION OF WIENER FILTER METHOD}

In order to validate the Wiener filter EMI estimation for hard switching inverter, data from accurate simulation has been used. The simulations have been performed with the

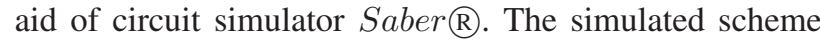
contains all circuit component models and connections including parasitic inductances and capacitances, using the same approach as in previous work for DC/DC boost converter [2]. The inverter simulations have been preformed in the time domain and then EMI spectra were calculated from the signal picked up by the LISN using fast Fourier transformation. The switches and the LISN voltage waveforms have shapes reflecting real application. These signals are sufficient to evaluate correct operation of Wiener filter and its proper operation using measured data from real hard switching inverter.
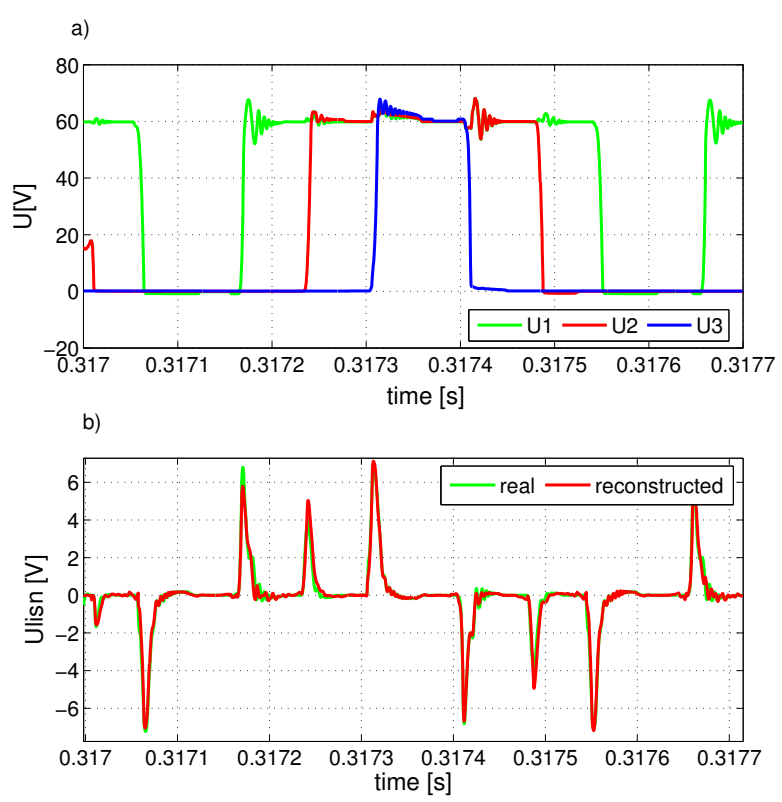

Fig. 4. The semiconductors and LISN voltage waveforms

In order to apply the Wiener filtering method, the new software has been built in Matlab $\mathbb{R}$ environment. The input signals are the inverter switch voltages $U_{1}, U_{2}$ and $U_{3}$ (figure 1), which are used first to detect inverter state and then to calculate perturbation. The total reconstructed 
signal is composition of signals achieved from all of 24 systems. The result of disturbances reconstruction is presented on figure 4.

It can be noticed that signals obtained by Wiener filtering are almost the same like the real ones. In this case, the normalized estimation error is $3.5 \%$. The inaccuracy can be explained by perturbations not correlated with the input voltages, interfered from another sources like load, transistors drivers or control system. Moreover in many digital signal processing algorithms, not sufficient number of samples can be a problem. As the DC/AC converter can stay in some states for a short time results in a low number of samples for these periods. In this case Saber $\mathbb{R}$ simulations have been effected with variable calculating step, producing non-regular number of samples per estimation period. Furthermore, using data from measurement as input signals, suitable number of samples should be assured in measurement equipment. Inappropriate Wiener filtering results can be observed on spectra, specially in high frequencies range.

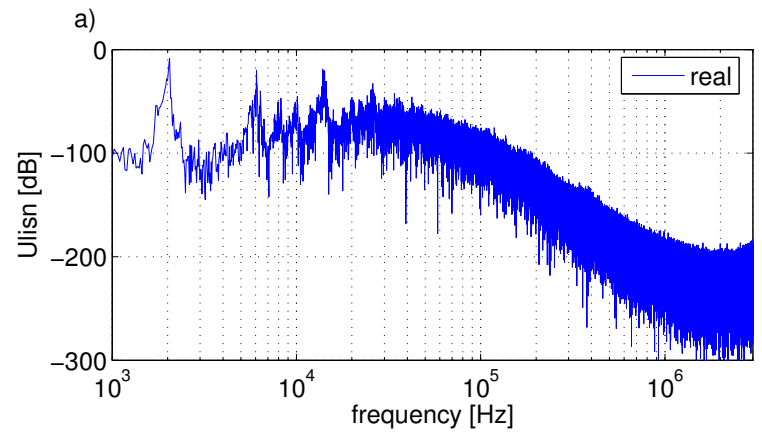

b)

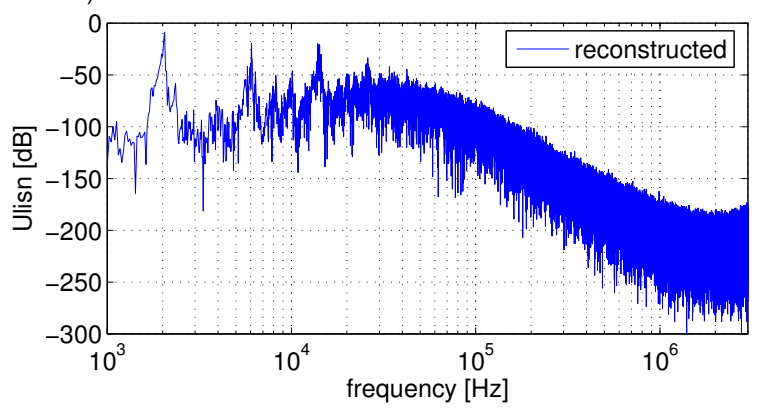

Fig. 5. The LISN voltage spectra a) simulation b) estimation

Comparative evaluation of the EMI simulation and estimation by Wiener filtering in the frequency domain is shown in figure 5. In high frequencies range, above $20 \mathrm{MHz}$, is indicated approximate estimation error of $2 \%$. In this case reconstruction of perturbations is quite precise, excepting this number samples discrepancy. In comparison with "typical" simulations, which need lots of computing time, powerful simulators and fast computers, Wiener filtering method is more effective as can be realized in a short time.

The identification of source disturbances can be obtained directly with this method: each part of perturbation waveform can be linked with the corresponding inverter
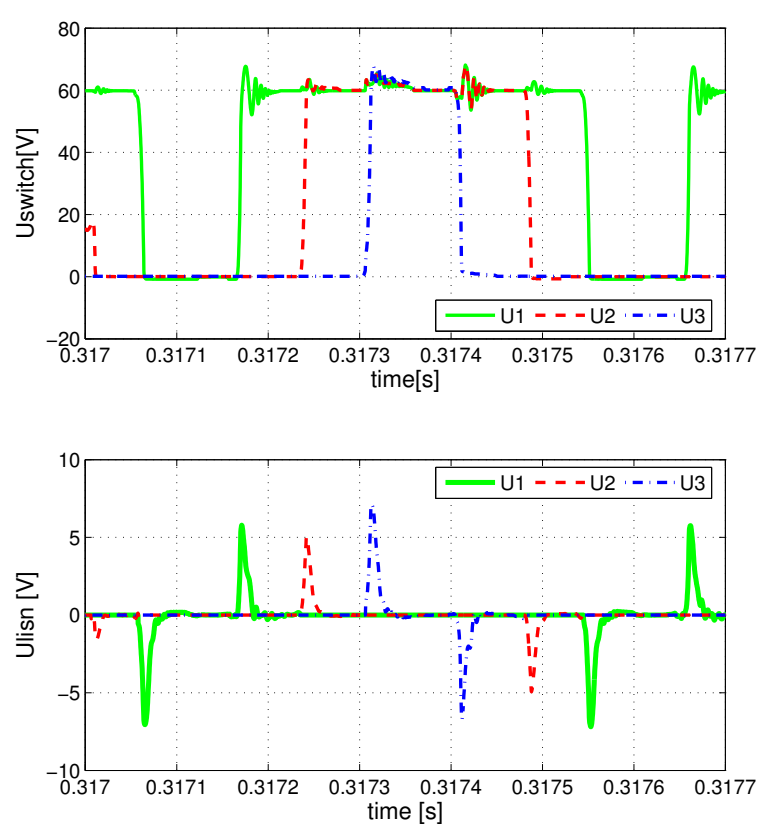

Fig. 6. The perturbations source identification

switch commutation voltage (fig. 6). It allows to separate perturbation generated by each particular switch. This knowledge is useful for optimization of geometrical layout and reductions of EMI emissions.

The main circuit property that the level of perturbations depends on inverter state, we try to prove in figure 7. Considering transfer functions of Wiener filter, of only one switch $\left(U_{1}\right)$, they are different for 4 inverter states (table I). The shape of transfer function depends on propagation path and participation of all parasitics components which take part in perturbations propagation. In spite of similar envelopes, the waveforms are completely different. In figure 7 we have also shown the different resonance frequencies which induce amplification of electromagnetic perturbations in some particular frequency bands.

Accurate EMI analysis for hard switching inverters should include all semiconductor states. However sometimes, the number of states can be smaller than proposed in this paper, because of existing symmetry in real power electronic applications.

Once the set of the transfer functions is known, it is possible to shape a source waveforms (voltages or current of semiconductors), that influence the perturbations shape and level.

To verify results obtained with simulation data in the above section, the conducted EMI of hard switching inverter has been measured. The perturbations reconstruction and source identification have been done using data from measurement. The hard switching inverter was supplied from traction battery $120 \mathrm{~V}$ through the LISN. The induction machine was used for a load. The measurement was realized with 4 channel oscilloscope Textronix TDS5034B with high voltage differential probes. 


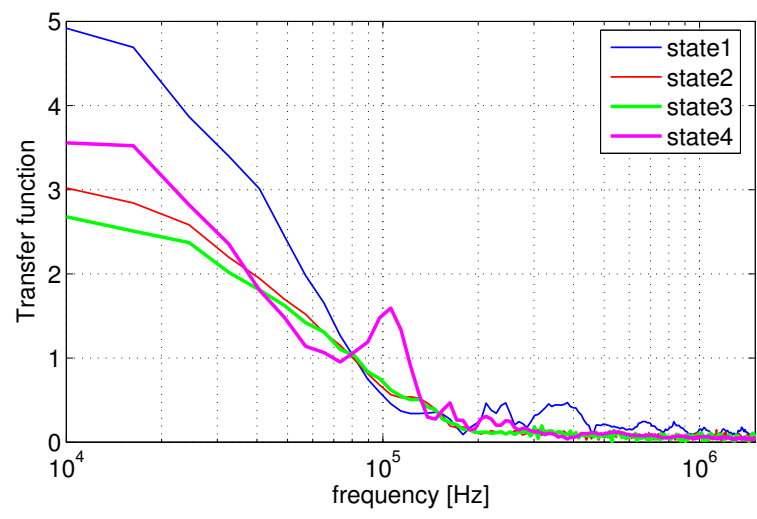

Fig. 7. The transfer functions for different states of inverter (table 1 p1-4))

a)
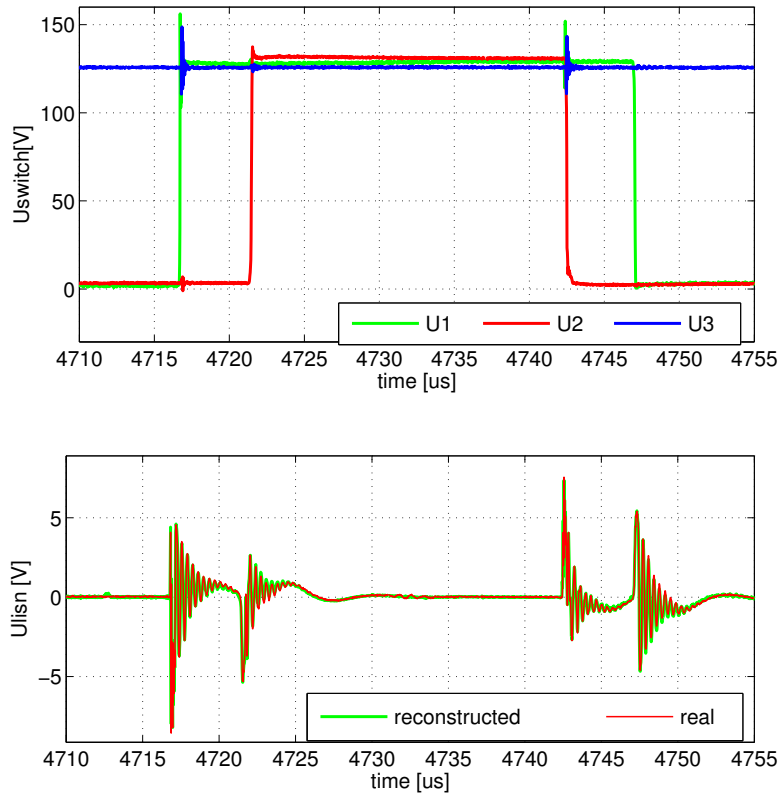

b)

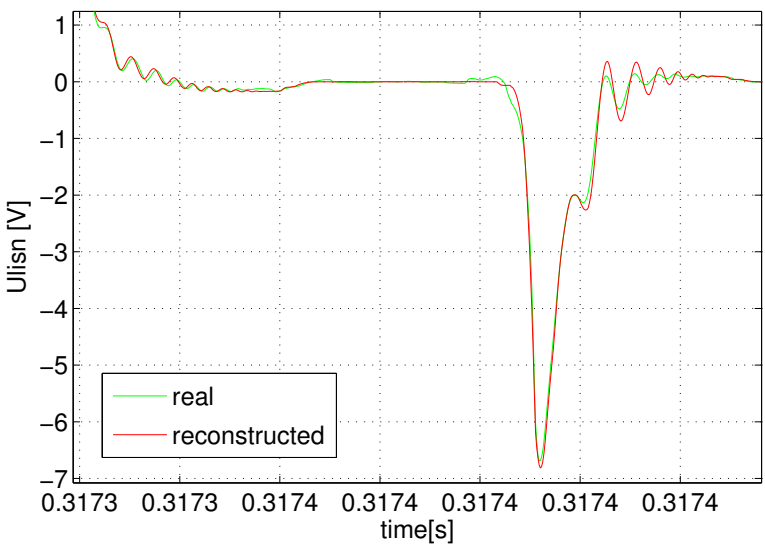

Fig. 8. The measured voltage of semiconductors and LISN waveforms for PWM modulation b) zoom

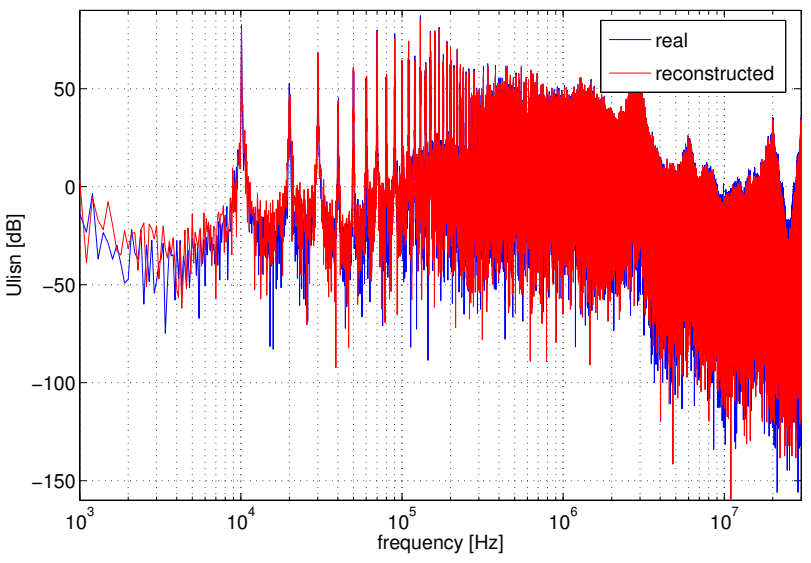

Fig. 9. The LISN voltage spectra for PWM modulation a) measured b) Wiener filter estimation
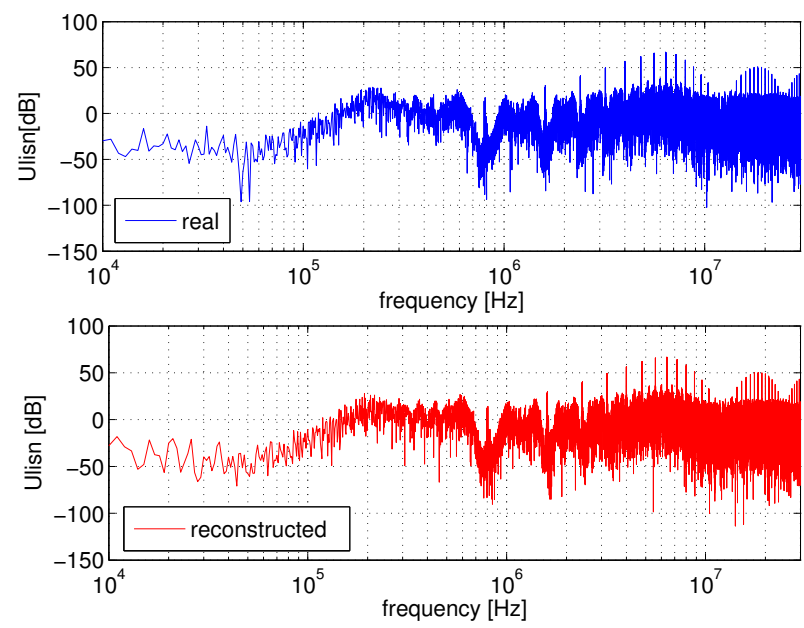

Fig. 10. The LISN voltage spectra for PDM modulation a) measured b) Wiener filter estimation

The waveforms have been registered with sampling frequency $50 \mathrm{MHz}$. The EMI generation for two kinds of modulation was carried out by:

- PWM - pulse width modulation

- PDM - pulse density modulation (sigma - delta)

The reconstruction of perturbations, generated by hard switching inverter with PWM modulation, using Wiener filtering works correctly, what is shown on figures 8 and 9 , where waveform and spectra of the measured LISN voltage is compared with the calculated one. The approximate estimation error is $3.3 \%$. It should be noticed that in real applications not all inverter states occur, but it does not influence on reconstruction accuracy.

The results of Wiener filtering of signals from inverter with PDM modulation are depicted in figure 11 . The reconstruction accuracy is also very high. The approximate estimation error does not exceed $3.7 \%$ in the whole emitted perturbation range (fig. 10). For PDM modulation, errors in transfer function calculation are slightly increased because of different number of samples for irregular inverter states. 
a)

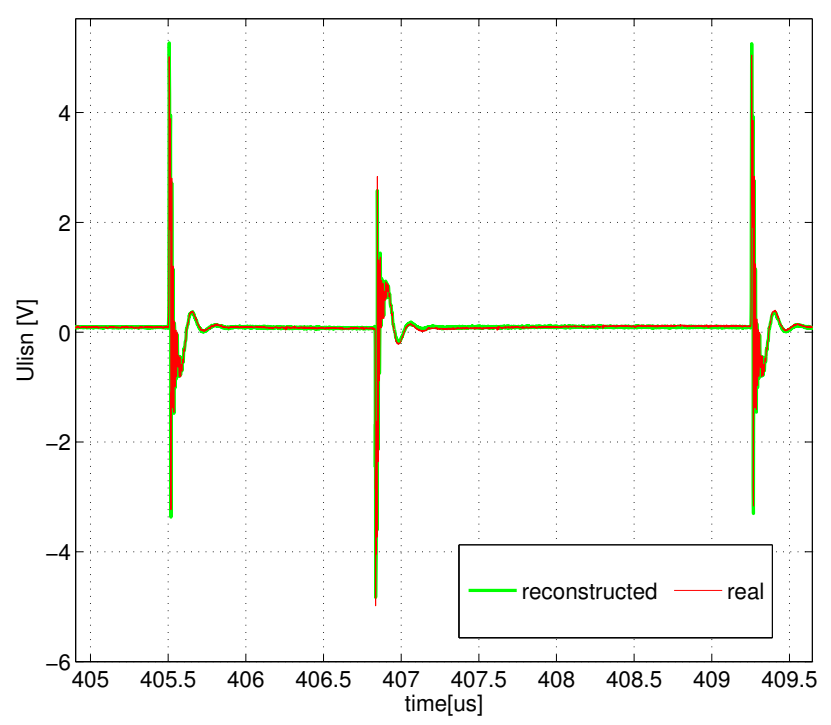

b)

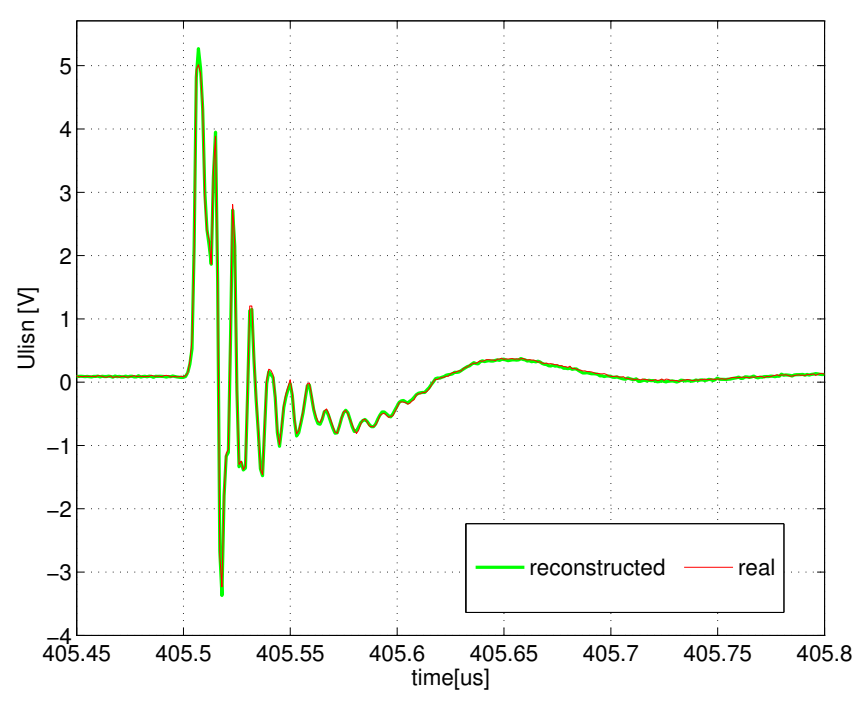

Fig. 11. The measured voltage of semiconductors and LISN voltage waveforms for PDM modulation b)zoom

\section{CONCLUSION}

This paper give a little step to better understanding of conducted EMI generation phenomena. A modeling with the digital signal processing approach has been described. Wiener filtering method allows to estimate with high sufficient accuracy EMI conducted emission in power electronics converters. Moreover, for perturbations estimation in hard switching inverter it is necessary to use several filters, because the level and waveform of perturbations strongly depend on system state. In this paper, method based on the 24 distinguished states is presented, that allows to reconstruct voltage registered on the LISN.
The analysis confirm that propagation path and contribution of inverter components are different for different state of inverter. Identification of commutation disturbances allows to link voltages across switches with perturbations. It is then possible to derive transfer function (impulse response in time domain) determine a relationship between the cause and effect of disturbances, that allows better understanding of EMI behavior of DC/AC hard switching inverter. Moreover, this technique can be useful for predicting EMI with different command laws, without any real implantation or time consuming simulation. Furthermore, this method could be used in EMC filter design, investigation of influence of modulation strategy on EMI level or development of new inverters topologies and models.

\section{REFERENCES}

[1] F.Costa, E.Laboure, F.Forest, S.Lefebvre ,Quantification and minimization of conducted interferences generated in hard switching and zero current switching cell", APEC'94, Conference Proceedings 1994., 1994, 615-621.

[2] P.Musznicki, JL.Schanen, B.Allard, P.J.Chrzan „Accurate modeling of layout parasitic to forecast EMI emitted from a DC-DC converter", PESC 04. 2004 IEEE 35th Annual, 2004, 1, pp. 278-283, Aachen, Germany.

[3] L Rossetto, G.Spiazzi, P Tenti „Boost PFC with $100 \mathrm{~Hz}$ switching frequency providing output voltage stabilization and compliance with EMC standards", IEEE Trans on IAS, Vol 36 n ${ }^{\circ} 1$ pp. 188-193 , Jan-Feb 2000

[4] B. Widrow et al., ,Adaptive noise cancelling: principle and applications", Proceedings of the IEEE 1975, Vol 63, Dec. 1975, pp. 1692-1716.

[5] B.Revol, J.Roudet, JL.Schanen, P.Loizelet „EMI study of a three phase inverter-Fed Motor Drives", IAS 04, Conference Record of the 2004 IEEE, 4, pp. 2657-2664

[6] JC.Crébier, J.Roudet, J.L.Schanen, „EMI analysis of single phase PFC boost rectifier in the frequency domain", Revue Internationale de Génie Electrique, Vol2 n ${ }^{\circ} 2$ 1999, pp 215-241.

[7] JL.Schanen, L.Jourdan, J.Roudet „Layout optimization to reduce EMI of a SMPS", Pesc 2002, IEEE 33rd Annual, 2002, 4, pp. 20212026

[8] S. V. Vaseghi ,Advance digital signal processing and noise reduction" 2000 John Wiley \& Sons Ltd

[9] P. Musznicki, JL. Schanen, P. Granjon. P.J. Chrzan „,Better understanding EMI generation of power converters" PESC 2005 June 2005, Recife, Brazil pp. 1052-1056

[10] M. Cacciato, A. Consoli, G. Scarcella, S. De Caro, A. Testa „High Frequency Modeling of DC/AC Converters" EPE 2005 September 2005 Dresden Germany

[11] JS.Lai, X.Huang, E.Pepa, SChen, TW.Nehl ,Inverter EMI modeling and simulation methodologies" EIECON '03. the 29th annual conference of the IEEE, Vol2, pp 1533-1539

[12] Q.Liu, F.Wang, D.Boroyevich ,,Model conducted EMI emission of switching modules for converter system EMI characterization and prediction" 39th IAS annual meeting. conference record of the 2004 IEEE, 3 , pp 1817-1823

[13] J. Ferreira, P.Willcock,S. Holm ,Sources, paths and traps of conducted EMI in switch mode circuits" IAS '97., Conference Record of the 1997 IEEE, 2, pp. 1584-1591

[14] A. Kempski, R.Smolenski, R.Strzelecki „Common mode current paths and their modeling in PWM inverter-feddrives” PESC 2002. IEEE 33rd Annual, 3, pp. 1551-1556

[15] L.Ran, S.Gokani, J.Clare, K. Bradley, C.Christopoulos ,C Conducted electromagnetic emissions in induction motor drive systems.II. Frequency domain models" , IEEE Transactions on Power Electronics, 1998, 13, pp. 768-776

[16] C.Serporta, G.Tine, G.Vitale, G. M.Di Piazza „Conducted EMI in power converters feeding AC motors: experimentalinvestigation and modelling" ISIE 2000. Proceedings of the IEEE International Symposium on, 2, pp. 359-364 